FETAL AND NEONATAL EDITION

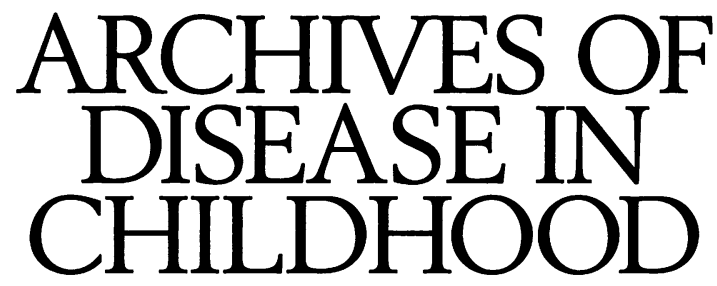

The fournal of the British Paediatric Association

\title{
Excitatory amino acids in neonatal brain: contributions to pathology and therapeutic strategies
}

Glutamate, the principal excitatory amino acid, is considered to be the major mediator of excitatory signalling and fast synaptic transmission in the central nervous system. The special importance of these signalling processes in the developing brain is starting to be appreciated. Glutamate evokes neuronal responses through well characterised, cell-surface receptors which were originally classified pharmacologically and more recently by molecular cloning as the ion channel-gating (ionotropic) $\alpha$-amino-3-hydroxy-5-methyl-4-isoxazole propionic acid (AMPA)/kainate (KA) receptor family, the N-methyl-Daspartate (NMDA) family, and the metabotropic family which is linked via G-proteins to intracellular signalling mechanisms. ${ }^{1-3}$ The AMPA/KA receptors mediate fast information transfer while the NMDA receptors seem only to function once the postsynaptic membrane has been depolarised. Most neurons as well as some glia seem to have glutamate receptors.

The extent to which receptors are activated is determined by extracellular glutamate concentrations. Apart from nerve terminal release, the other major influence on extracellular glutamate is the activity of specific uptake transporters, found on nerve terminals and surrounding glia (astrocytes). Their purpose is to maintain low extracellular concentrations of glutamate to keep a balance between effective signalling and excitotoxicity. ${ }^{4}$ The conditions which cause glutamate to be released can also produce energy depletion and ion imbalances which can lead to failure of uptake transporters or even drive them in reverse, ${ }^{5}$ thus releasing more glutamate, raising extracellular concentrations even further, and incurring excitotoxicity and a chain of events leading to neuronal damage.

\section{Excitotoxicity}

Experimental studies have shown that excitotoxicity is triggered by excessive release and extracellular overflow of glutamate which causes overactivation of receptors. There is overwhelming evidence that an excessive concentration of extracellular glutamate and other excitatory amino acids has a crucial role in the pathogenesis of neuronal death following brain ischaemia, trauma, seizures or, especially in the developing brain, hypoglycaemia. The neonatal brain may be exposed to any of these. In fetal sheep brain extracellular glutamate concentrations rose several-fold during ischaemia and hypoglycaemia. ${ }^{67} \mathrm{~A}$ feature of the usual sites of perinatal neuronal injury - hippocampus, cerebellum, basal ganglia - is the presence of many glutamate neurons. ${ }^{8}$ Finding ways to overcome glutamate excitotoxicity is a major therapeutic goal irrespective of age, but the neonate presents special problems because of the immaturity of the glutamate system and the fact that glutamate has special functions in the developing brain.

The principal approach used to overcome glutamate excitotoxicity is to design glutamate receptor blocking agents. The AMPA/KA receptors mainly depolarise neurons through sodium influx rather than calcium influx, because this receptor family triggers few calcium dependent processes. ${ }^{9}$ Protracted glutamate release and intense AMPA/KA stimulation can cause enough sodium influx to produce neuron damaging oedema. Furthermore, the neuron depolarisation also provokes NMDA receptor activation and subsequent entry of calcium. This triggers a network of enzyme cascades and messengers, leading inevitably to cell death. ${ }^{1011}$ Thus both AMPA/KA and NMDA receptor blockers may achieve similar therapeutic goals.

\section{Glutamate as a growth regulator}

Whenever a brain neurotransmitter takes on a developmental role, especially during periods of rapid synapse production, both the nerve terminals and postsynaptic receptors may be temporarily overexuberant. Early modulation of these so-called precocious receptors may influence neural growth. ${ }^{12}$ The glutamate system may influence neurite sprouting, synaptogenesis, dendrite pruning and whether neurons survive developmental or pathological attrition. NMDA receptors in particular may coordinate synaptogenesis and synaptic plasticity in developing brain. ${ }^{12}$ Thus NMDA receptor activation was essential to promote neurite outgrowth from cerebellar cells, ${ }^{13}$ and whereas AMPA/KA receptors regulated growth of young hippocampal cell cultures, NMDA receptors assumed control in mature cell cultures. ${ }^{14}$

\section{The glutamate NMDA receptor}

NMDA receptors in neuronal membranes control channels which allow calcium ions to enter neurons. The 


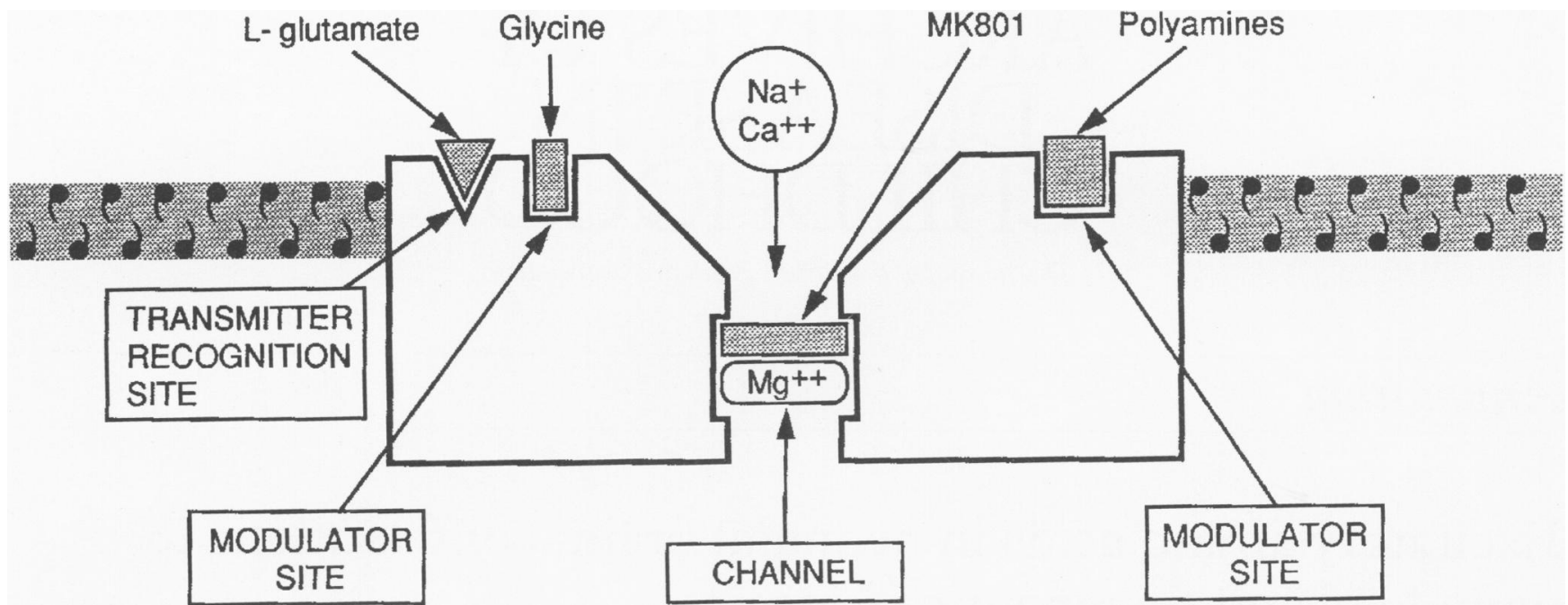

A model for the NMDA receptor complex in neuronal membranes which illustrates the main target sites for compounds that may be used to tone down or block directly the opening of the calcium permeable channel.

channels are normally blocked by magnesium unless the neuron is depolarised - for instance, when other glutamate receptors (AMPA, metabotropic) are activated. Excessive release of glutamate is generally required before NMDA channels open to calcium. ${ }^{15}$ This regulation of cell calcium by glutamate lies behind the phenomenon of long term potentiation (LTP), a type of synaptic plasticity (allied to memory) that is normally observed in the glutamate rich hippocampus. ${ }^{16}$

Nitric oxide (NO) is synthesised by NO synthase (NOS) following activation by glutamate of NMDA receptors and it can diffuse through brain membranes. These properties make NO a promising candidate for a retrograde messenger in brain. NO is believed to play a part in the induction of LTP, because NOS inhibitors block LTP by a process that can be reversed by L-arginine ${ }^{17}$ Haemoglobin, which binds and inactivates NO, is also known to block LTP. ${ }^{17}$ One of the actions of $\mathrm{NO}$ as a retrograde messenger may be to facilitate glutamate release. ${ }^{18}$

The messenger or neuromodulator roles of NO may also include a role in the refining of neural connections during brain development. These processes, which may be related to LTP, ${ }^{19}$ have implications for memory and learning. Thus suppression of LTP may occur in post-traumatic head injury which damages hippocampal neurons rich in NMDA and causes profound memory and learning dysfunction. ${ }^{20}$

The NMDA receptor complex (figure) is highly unusual in having multiple sites which, in different ways, can control channel opening and therefore calcium flux. These modulatory sites recognise glutamate (the NMDA site) as well as glycine and polyamines (spermine and spermidine). The channel lumen has other sites, some recognised by magnesium and others by phencyclidine (PCP) - like drugs, including the anaesthetic ketamine and the anticonvulsant MK-801 (Dizocilpine). Channels can therefore be opened by glutamate, glycine, or a polyamine. These may be most effective in concert, or blocked pharmacologically by glutamate, glycine, and polyamine antagonists (site blockers), or by $\mathrm{MK}-801$ and similar channel site compounds. Experimentally, NMDA channel opening is assessed by how much $\left[{ }^{3} \mathrm{H}\right] \mathrm{MK}-801$ binding can be measured. ${ }^{21}$ What is so special about the NMDA receptor is its multiple targets for potential therapeutic agents that can tone down channel opening.
Receptors are transmembrane proteins expressed by appropriate messenger RNA (mRNA). NMDA receptors are assembled from two molecular families: NMDA-R1 and NMDA-R2. The latter comprises four subunits $(-2 A$ to $-2 D) .{ }^{22} 23$ NMDA receptors in different parts of brain are assembled from different subunit combinations but NMDA-R1 may be obligatory for a functioning receptor. ${ }^{22}$ In vitro studies suggest that functioning NMDA receptors may not always possess all the recognition sites. ${ }^{24}$ Once it is known how human brain NMDA receptors are assembled, it may be possible to introduce pharmacological agents which have some degree of regional selectivity for brain NMDA receptors.

\section{Postnatal development of glutamate neurons}

Some glutamate transporter sites are found on glutamate neurons and terminals and therefore provide an idea of the density of these elements. Term newborn infants had fewer transporter sites in areas of brain which in adults have many glutamate neurons. ${ }^{25}{ }^{26}$ Reasons for this may be that glutamate nerve terminals in neonatal brain are sparse or functioning subnormally. Infant brain during development soon acquires more transporter sites, particularly in the cortex and cerebellum, which continue to appear until they are overabundant by the end of the first year. ${ }^{2526}$ The apparent postnatal growth spurt in glutamate nerve terminals coincides with a rapid production of synapses. Brains of infants or children develop exuberant synapses which are slowly pruned up to adolescence. ${ }^{27}$

\section{Postnatal development of glutamate receptors}

Developing mammalian brains may show brief and modest overexpression of glutamate receptors which do not necessarily coincide with synapse production and elimination. In human hippocampus AMPA receptors peak prenatally but decline by 26 weeks' gestation, ${ }^{28}$ long before the bulk of synaptogenesis.

An early report described a transient postnatal rise in hippocampal NMDA receptors in the human infant. ${ }^{29}$ The glycine and MK-801 (channel) sites of the NMDA complex in term infant cortex start to increase at one week after birth and by about 20 weeks are overexpressed, greatly exceeding levels found in adult brain. ${ }^{30} 31$ 
Examples of compounds in each class of NMDA receptor antagonists with potential neuroprotective properties

\begin{tabular}{ll}
\hline Mode of action & Selective antagonists \\
$\begin{array}{l}\text { Competitive block of the transmitter } \\
\text { recognition site }\end{array}$ & D-AP7, CGS 19755, CPP \\
Blocking the NMDA-coupled ion & Ketamine, phencyclidine, Dizocilpine \\
channel & (MK-801) \\
Blocking the polyamine site & Arcaine, Eliprodil, Ifenprodil \\
Blocking the glycine site & 7-Chlorokynurenic acid, (+)-HA-966, \\
& $5,7-$ dichlorokynurenic acid, \\
& L-678,414
\end{tabular}

Furthermore, the ability of glutamate and glycine to increase $\left[{ }^{3} \mathrm{H}\right] \mathrm{MK}-801$ binding and thus stimulate opening of NMDA-coupled channels was most effective in 20 week old infant brain, suggesting that the NMDA receptor complex is also hyperresponsive. ${ }^{32}$

It may be a general rule that some NMDA regulatory sites in mammalian brain show differential development. ${ }^{12}$ In man, brains from older infants have excess glycine modulatory sites compared with adult brain. ${ }^{30} 31$ Thus, without doubt, growth of NMDA receptors in the human infant is far more pronounced than that in experimental animals.

Animal studies have shown that the relative proportions of the mRNA which express the NMDA subunits are different in neonatal and adult brains, implying that there is a postnatal reassembly of subunits to acquire the composition of adult brain NMDA receptors. The importance of this, in view of the fact that some NMDA subunits may not have their full complement of modulatory sites, is that the pharmacological properties as well as the functions of NMDA receptors alter during development. Thus NMDA blockers suited to adult brain may be less appropriate for neonatal brain in which NMDA receptors may have functions better suited to their developmental roles and may be guided into a molecular rearrangement as mature brain functions take over. The molecular reorganisation of NMDA receptors in man has yet to be worked out, but the fact that infant brain acquires plenty of NMDA receptors, as revealed by the $\mathrm{MK}-801$ channel sites, as well as lots of glycine sites, ${ }^{30-32}$ suggests that receptor subunits with glycine sites are particularly overexpressed. NMDA receptors reach their highest densities around the end of the first year and decline in childhood until they slowly reach adult levels. ${ }^{30-33}$ This suggests that levels of the mRNA responsible for some NMDA subunits rise and fall during the protracted molecular reconfiguration of NMDA receptors in human brain.

Conventional receptor binding studies on rat brains have confirmed that NMDA receptors change some of their properties in early postnatal life, ${ }^{34} 35$ probably at the same time as their molecular reorganisation. ${ }^{23}$ This may be to enable NMDA receptors in developing brain to lose whatever properties are required to guide neuronal migration and synapse elimination as these become less important in adult brain. NMDA receptor subunit switchover during development may be pre-programmed and also use dependent. One of the pieces of research still to be carried out is to discover whether intrauterine growth retardation, preterm birth, or neonatal complications affect the way NMDA receptors are assembled and how they subsequently function.

\section{Glutamate receptors and their potential for treatment}

Many experimental studies have reported how all kinds of glutamate receptor blockers can be neuroprotective in those conditions believed to involve excess glutamate (table), although many incur severe side effects. ${ }^{43}{ }^{44}$ Most attention has focused on NMDA blockers which may offer better protection against focal rather than global brain ischaemia. Both ischaemia and seizures may induce high concentrations of glutamate, so substances which produce a non-competitive type of block may be best because such a block is harder to overcome. Furthermore, non-competitive channel site blockers have the extra benefit of affecting those sites which are exposed (for example, MK-801) by excess glutamate. However, a more effective strategy for protecting against glutamate excitotoxicity might combine an AMPA/KA receptor blocker with an NMDA blocker.

Any drug which may eventually be used to guard against excitotoxicity in the neonate may have to be both short acting and relatively mild in its effects on NMDA receptors, to avoid misdirecting the development of the glutamate system at a critical period. There is obvious concern that this might influence subsequent brain development. The possible consequences of such deviant development are not clearly understood.

NMDA channel blockers thought to have some therapeutic potential include, or may be based on, MK-801 and the dissociative anaesthetic ketamine. Both have known side effects which restrict their use, such as behaviour disorders and cognitive deficits, whilst MK-801 causes vacuolation of neurons and their destruction at high doses. Dextromethorphan is an established (antitussive) drug is a relatively weak NMDA blocker whose mechanism of action is uncertain. Although dextromethorphan may cause a reversible neuronal vacuolation with ataxia and neurobehavioural side effects at higher doses, it has proved valuable in overcoming the neurological consequences of hyperglycinaemia in infants. ${ }^{45}$ Remacemide is an anticonvulsant, neuroprotective compound with antagonist activity at the NMDA receptor ion channel. It can induce hyperactivity, ataxia, and behaviour disorders and perhaps some neuronal vacuolation. Memantine, whose structure is different from other NMDA channel blockers, may have similar side effects to the dissociative anaesthetics, causing agitation, confusion, and psychotic symptoms.

Non-competitive AMPA/KA receptor blockers, including some 2,3 benzodiazepines, have recently been identified. The anticonvulsant and AMPA blocker NBQX was neuroprotective in brain ischaemia models. Barbiturates appear to block AMPA/KA receptors in a non-competitive way but they are obsolete. GYK 152466 is a non-competitive antagonist that is effective in animal models of global and focal brain ischaemia.

So far, animal studies have produced data which suggest that non-competitive NMDA and AMPA/KA receptor antagonists may protect against cellular damage. Dextromethorphan, ${ }^{45}$ remacemide, and memantine approach clinical acceptability and without doubt new compounds are being investigated.

\section{NO and excitotoxicity}

NO produced in brain as a consequence of glutamate NMDA receptor activation is a membrane diffusible free radical which, in high concentrations, is neurotoxic. Conditions such as ischaemia, which give rise to intense NMDA receptor stimulation, may also cause the production of excess NO and thus exacerbate excitotoxicity. NO may also interact with glutamate systems in various ways, including facilitating glutamate release ${ }^{18}$ which could raise extracellular glutamate concentrations even further. The role of NO in causing brain damage in cerebral ischaemia is therefore being investigated and early reports suggest that NOS inhibitors can be neuroprotective. It is too soon to predict whether any therapeutic agents will ever emerge 
but research into NO will undoubtably be a major source of important new findings.

This research was supported by Action Research.

S W D'SOUZA

Department of Child Health,

University of Manchester,

St Mary's Hospital.

Hathersage Road,

Manchester M13 OfH

School of Biological Sciences,

P SLATER

Stopford Building

University of Manchester,

Manchester M13 9PT

1 Monaghan DT, Hosts VR, Toy DW, Cotman CW. Anatomical distributions of four pharmacologically distinct ${ }^{3} \mathrm{H}$-L-glutamate binding sites. Nature 1983; 306: 426-79.

2 Greenamyre JT, Olsen JM, Penny JB, Young AB. Autoradiographic characterization of $\mathrm{N}$-methyl-D-aspartate-, quisqualate- and kainate-sensitive glutamate binding sites. $\mathcal{F}$ Pharmacol Exp Ther 1985; 233: 254-63.

3 Monaghan DT, Bridges RJ, Cotman CW. The excitatory amino acid receptors: their classes, pharmacology and distinct properties in the function of the central nervous system. Annu Rev Pharmacol Toxicol 1989; 29: 365-402.

4 Danbolt NC. The high affinity uptake system for excitatory amino acids in the brain. Progr Neurobiol 1994; 44: 377-96.

5 Nichols D, Attwell D. The release and uptake of excitatory amino acids. Trends Pharmacol Sci 1990; 11: 462-8.

6 Hagberg H, Lehmman A, Sandberg M, Nyström B, Jacobson I, Hamberger A. Ischaemia-induced shift of inhibitory and excitatory amino acids from intraIschaemia-induced shift of inhibitory and excitatory amino acids from intra-

7 Sandberg M, Butcher SP, Hagberg H. Extracellular overflow of neuroactive amino acids during severe insulin-induced hypoglycaemia. In vivo dialysis of the rat hippocampus. $\mathcal{F}$ Neurochem $1986 ; 47: 178$

8 Clarke GD. Role of excitatory amino acids in brain injury caused by hypoxia-ischemia, status epilepticus and hypoglycaemia. Clin Perinatol 1989; 16: 459-74

9 Seeburg PH. The TiPS/TINS lecture: The molecular biology of mammalian glutamate receptor channels. Trends Pharmacol Sci 1993; 14: 297-303.

10 Choi DW. Glutamate neurotoxicity and diseases of the nervous system. Neuron 1988; 1: 623-4.

11 Choi DW. Bench to bedside: the glutamate connection. Science 1992; 258: 241-3.

12 McDonald JW, Johnston MV. Physiological and pathophysiological roles of excitatory amino acids during central nervous system development. Brain Res Rev 1990; 15: 41-70.

13 Pearce IA, Cambray-Deakin MA, Burgoyne RD. Glutamate acting on NMDA receptors stimulates neurite outgrowth from cerebellar granule cells. FEBS Lett 1987; 223: 143-7.

14 Mattson MP, Dou P, Kater SB. Outgrowth-regulating actions of glutamate in isolated hippocampal pyramidal neurons. F Neurosci 1988; 8: 2087-100.

15 Garthwaite J. NMDA receptors, neuronal development and neurodegeneration. In: Watkins JC, Collingridge GL, eds. The NMDA receptor. Oxford: IRL Press, 1989: 187-205.

16 Lynch G, Larson J, Kelson S, Barrionuevo G, Schottler F. Intracellular injections of EGTA block induction of hippocampal long-term potentiation. Nature 1983; 305: 719-21.

17 O'Dell TJ, Hawkins RD, Kandel ER, Arancio O. Tests of the roles of two diffusible substances in long-term potentiation: evidence for nitric oxide as a possible early retrograde messenger. Proc Natl Acad Sci USA 1991; 88: a possible

18 Lawrence AJ, Jarrott B. Nitric oxide increases interstitial excitatory amino acid release in the rat dorsomedial medulla oblongata. Neurosci Lett 1993; 151: 126-9.

19 Kandel ER, O'Dell TJ. Are adult learning mechanisms also used for development. Science 1992; 258: 243-5.

20 Smith DH, Okiyama K, Thomas MJ, Claussen B, McIntosh TK. Evaluation of memory dysfunction following experimental brain injury using the Morris water maze. F Neurotrauma 1991; 8: 259-69.

21 Reynolds IJ, Miller RJ. Multiple sites for the regulation of the N-methyl-Daspartate receptor. Mol Pharmacol 1988; 33: 581-4.
22 Monyer H, Sprengel R, Schoepfer R, Herb A, Higuchi M, Lomeli H, et al. Heteromeric NMDA receptors: molecular and functional distinction of Heteromeric NMDA receptors: molec

23 Monyer $\mathrm{H}$. Developmental expression of four NMDA receptor sub-types. Eur 7 Neurosci 1994; 819 (suppl 6): 211.

24 Le Bourdelles B, Wafford KA, Kemp JA, Marshall G, Bain C, Wilcox AS et al. Cloning, functional co-expression and pharmacological characterization of human cDNAs encoding NMDA receptor NR1 and NR2A subunits. F Neurochem 1994; 62: 2091-8.

25 Slater P, McConnell S, D'Souza SW, Barson AJ, Simpson MDC, Gilchris AC. Age-related changes in binding to excitatory amino acid uptake site in temporal cortex of human brain. Dev Brain Res 1992; 65: 157-60.

26 Slater P, McConnell SE, D'Souza SW, Barson AJ. Age-related changes in binding to excitatory amino acid uptake sites in human cerebellum. Brain Res 1992; 579: 219-26.

27 Huttenlocher PR. Morphometric study of human cerebral cortex development. Neuropsychologia 1990; 28: 517-27.

28 Lee H, Choi BH. Density and distribution of excitatory amino acid receptors in the developing human fetal brain: a quantitative autoradiographic study. Exp Neurol 1992; 118: 284-90.

29 Kornhuber J, Retz W, Riederer P, Heinsen H, Fritze J. Effect of antemortem and postmortem factors on $\left[{ }^{3} \mathrm{H}\right]$ glutamate binding in the human brain. Neurosci Lett 1988; 93: 213-7.

30 D'Souza SW, McConnell SE, Slater P, Barson AJ. N-methyl-D-aspartate binding sites in neonatal and adult brain. Lancet 1992; 339: 1240

31 D'Souza SW, McConnell SE, Slater P, Barson AJ. Glycine site of the excitatory amino acid N-methyl-D-aspartate receptor in neonatal and adult brain. Arch Dis Child 1993; 69: 212-5.

32 Slater P, McConnell SE, D'Souza SW, Barson AJ. Postnatal changes in Nmethyl-D-aspartate receptor binding and stimulation by glutamate and glycine of $\left[{ }^{3} \mathrm{H}\right] \mathrm{MK}-801$ binding in human temporal cortex $\mathrm{Br} f$ Pharmacol 1993; 108: 1143-9.

33 Court JA, Perry EK, Johnson M, Piggott MA, Kerwin JA, Perry RH, et al. Regional patterns of cholinergic and glutamate activity in the developing and aging human brain. Dev Brain Res 1993; 74: 73-82.

34 Williams K, Hanna JL, Molinoff PB. Developmental changes in sensitivity of the N-methyl-D-aspartate receptor to polyamines. Mol Pharmacol 1991, 40: $774-82$.

35 Williams K, Russell SL, Shen YM, Molinoff PB. Developmental switch in the expression of NMDA receptors occurs in vivo and in vivo. Neuron 1993; 10: 267-78.

36 Davies J, Evans RH, Herling PL, Jones AW, Olverman HJ, Pook P, et al. CPP, a new potent and selective NMDA antagonist. Depression of central neuron responses, affinity for $\left.{ }^{3} \mathrm{H}\right] \mathrm{D}-\mathrm{AP} 5$ binding sites on brain membranes and anticonvulsant activity. Brain Res 1986; 382: 169-73.

37 Anis NA, Berry SC, Burton NR, Lodge D. The dissociative anaesthetics, ketamine and PCP, selectively reduced excitation of central mammalian neurones by $\mathrm{N}$-methyl-D-aspartate. $\mathrm{Br} f$ Pharmacol 1983; 79: 565-75.

38 Wong EHF, Kemp JA, Priestly T, Knight AR, Woodruff GN, Iversen LL. The anticonvulsant MK-801 is a potent N-methyl-D-aspartate antagonist. Proc Natl Acad Sci USA 1986; 83: 7104-8.

39 Williams K. Ifenprodil discriminates subtypes of the N-methyl-D-aspartate receptor: selectivity and mechanisms at recombinant heteromeric receptors. Mol Pharmacol 1993; 44:851-9.

40 Kemp JA, Foster AC, Leeson PD, Priestly T, Tridgett R, Iversen LL, et al. 7 -Chlorokynurenic acid is a selective antagonist at the glycine modulatory site of the N-methyl-D-aspartate receptor complex. Proc Natl Acad Sci USA 1988; 85: 6547-50.

41 Singh L, Donald AE, Foster AC, Hutson PH, Iversen LL, Iversen SD, et al. Enantiomers of HA-966 (3-amino-1-hydroxypyrrolid-2-one) exhibit distinct central nervous system effects: $(+)-\mathrm{HA}-966$ is a selective glycine/N-methyl-D-aspartate receptor antagonist, but $(-)$-HA-966 is a potent $\gamma$-butyrolactone-like sedative. Proc Natl Acad Sci USA 1990; 87: potent $\gamma$ - 1 .

42 Tricklebank MD, Bristow LJ, Hutson PH, Leeson PD, Rowley M, Saywell $\mathrm{K}$, et al. The anticonvulsant and behavioural profile of $\mathrm{L}-687,414$, a partial agonist acting at the glycine modulatory site on the N-methyl-D-

43 Meldrum BS, ed. Excitatory amino acid antagonists. London: Blackwell Scldrum BS, ed. Excitatory

44 Rogawski MA. Therapeutic potential of excitatory amino acid antagonists: channel blockers and 2,3 benzoidazepines. Trends Pharmacol Sci 1993; 14: 325-31.

45 Hamosh A, MacDonald JW, Valle D, Francomanus CA, Niedermeyer E, Johnston MV. Dextromethorphan and high dose benzoate therapy for nonketotic hyperglycinaemia in an infant. $\mathcal{F}$ Pediatr 1992; 121: 131-5. 